\title{
Risk aversion in macaques in a freely moving patch-leaving foraging task
}

\author{
Eisenreich, B. R. and Benjamin Y. Hayden
}

Department of Neuroscience and

Center for Magnetic Resonance Research,

University of Minnesota,

Minneapolis MN 55455

\section{Corresponding author:}

Benjamin R. Eisenreich

Department of Neuroscience

University of Minnesota

Minneapolis, MN, 55455

Email address: benjaminr.eisenreich@gmail.com

\section{Funding statement}

This research was supported by a National Institute on Drug Abuse Grant R01 DA038106 (to BYH) and a NIH T32 to BRE.

\section{Competing interests}

The authors have declared that no competing interests exist.

Conflict of interest: Both authors declare no conflicts of interest. 
ABSTRACT

43 is the rhesus macaque (Macaca mulatta), which is robustly risk-seeking. Macaques'

44 unique preferences may reflect their unique evolutionary history. Alternatively, they may

45 derive from elements of task design associated with the demands of physiological

46 recording, the source of nearly all macaque risk preference data. To disambiguate these

47 possibilities we assessed macaques' risk attitudes in a somewhat more naturalistic

48 environment: subjects foraged at four feeding stations in a large enclosure. Stations (i.e.

49 patches) provided either stochastically or non-stochastically depleting rewards. Subjects'

50 patch residence times were longer at safe than at risky stations, indicating a preference

51 for safe options. This preference was not attributable to a win-stay-lose-shift heuristic.

52 These findings highlight the lability of risk attitudes in macaques and support the

53 hypothesis that observed differences between macaques and other species are ephemeral,

54 not evolved.

$55 \quad$ Keywords: risk, economics, foraging, rhesus macaques 


\section{INTRODUCTION}

59 Many animals, including humans, prefer sure things to gambles (Kacelnik \&

60 Bateson, 1996). The tendency to minimize risk (i.e. unknowable and unpredictable

61 variation) has been a topic of interest from behavioral ecology (Heilbronner, 2017;

62 Stephens \& Krebs, 1986) to economics (Kanheman \& Tversky, 1979; O’Donoghue \&

63 Somerville, 2018) and neuroscience (Genest et al., 2016; Knutson \& Bossaerts, 2007;

64 Mccoy \& Platt, 2005; Preuschoff et al., 2008; Strait et al., 2014; Calhoun and Hayden,

65 2015). Furthermore, cognitive processes related to decision making in risky contexts

66 underlies many maladaptive behaviors such as addiction and problem gambling (Peters et

67 al., 2016; Wilson \& Vassileva, 2018). Consequently accurately understanding risk

68 attitudes provides important insight into the evolutionary origin, and thus the

69 psychological and neural mechanisms, of addiction and maladaptive choice (Rosati and

70 Santos Annual Reviews).

71 Most animals are risk averse (Kacelnik \& Bateson, 1996). For example, bumble

72 bees, rats, starlings, and humans all demonstrate reliable risk aversion in standard

73 experimental tasks (Kagel et al., 1986; Marsh \& Kacelnik, 2002; Real, 1990; Weber et

74 al., 2004). Other risk-averse animals include fish, pigeons, juncos, warblers, jays, and

75 shrews (Kacelnik \& Bateson, 1996). In marked contrast, rhesus macaques are robustly

76 risk-seeking (Genest et al., 2016; Hayden \& Platt, 2007; Mccoy \& Platt, 2005; O’Neill \&

77 Schultz, 2010; So \& Stuphorn, 2010; Stauffer et al., 2015; Xu \& Kralik, 2014).

78 Macaques' exceptional risk preferences represent an abnormality under many theories of 
79 decision-making. For example, they are not consistent with the presumptions of prospect

80 theory, probably the most widely used behavioral economic approaches to studying risk

81 (Kanheman \& Tversky, 1979). Meanwhile, scalar utility theory, which is based on

82 granular psychological principles, predicts risk aversion due to inherent noise in memory

83 processes for rewards (Kacelnik \& Abreu, 1998). Even risk sensitive foraging theory

84 (Caraco, 1981), which predicts risk-seeking as an adaptive strategy to energetically poor

85 environments and deprived physiological states, does not fully explain macaque risk

86 attitudes as experimental deprivation increases greater risk aversion in contradiction of

87 the prediction of increased risk-seeking (Yamada et al. 2013).

88 Explanations for why macaques differ from other animals generally come in two

89 types. One type of explanation assumes that macaques' risk attitudes are an evolved

90 reflection of their foraging history. Evolutionary factors that could promote risk-seeking

91 in macaques include their specific feeding ecology and social structure (Heilbronner et

92 al., 2008; Stevens et al., 2005; Santos \& Rosati, 2015). For example, rhesus macaques

93 forage in social groups on a wide range of herbaceous resources including human crops,

94 as well as insects (Richard et al., 1989). Their broad diet allows for greater tolerance of

95 variability within a resource due to many readily available alternatives. This tolerance for

96 variability may reflect in their tolerance for variable options in economic tasks.

97 Another possibility is that macaques' risk-seeking is a measurement artifact. The

98 manner in which macaques' risk attitudes are measured is generally different from

99 methods used for other species (Hayden \& Platt, 2009; Heilbronner, 2017; Heilbronner \&

100 Hayden, 2013). Macaques are a popular model organism for neurophysiological studies

101 of decision-making. Their risk attitudes tend to be assessed in contexts tailored to the 
102 needs of electrophysiology, not cross-species comparison. Thus they are tested with rapid

103 trials (often as fast as three seconds per trial), small stakes, abstract stimuli, immediate

104 rewards, overtraining, oculomotor responses, and hundreds or thousands of trials in a few

105 hours. It may be that one of these factors, or some combination thereof, motivate risky

106 choice. Indeed, even humans can become risk-seeking when gambling for small rewards

107 in conditions designed to be similar to those used in non-human primate experiments

108 (Hayden \& Platt, 2009). And even modest changes, like slowing the pace of decisions by

109 inserting inter-trial intervals, markedly reduces (but does not eliminate) risk-seeking in

110 macaques (Hayden \& Platt, 2007). Likewise, using token rewards alters other patterns of

111 risk preferences, although it does not eliminate risk-seeking (Farashahi et al., 2018).

112 We hypothesized that with greater effort to make decisions more natural, we

113 could make macaques risk-averse, and thus match behavior found in other species. We

114 designed a naturalistic foraging task based on the patch-leaving problem from foraging

115 theory (Stephens \& Krebs, 1986; Charnov 1976; Nonacs, 2001). We tested subjects (n=3)

116 using a single subject design within a large enclosure that allowed for free movement

117 between different feeding stations. Our task design incorporates risk within the

118 stochasticity of patch harvests rates (consequently, risk is orthogonal to reward amount).

119 We allowed for self-governed allocation of behavior among patches. Thus, we are able to

120 examine the influence of risk across the use of patch types in addition to within particular

121 patches. We found that macaques are risk-averse under these foraging conditions. Two of

122 the same subjects exhibited risk-seeking in a standard risk task designed for physiological

123 recording, indicating that their risk preferences are task-specific, not individual-specific.

124 Taken together, our results demonstrate the impact of the environmental structure on the 
bioRxiv preprint doi: https://doi.org/10.1101/452151; this version posted October 25, 2018. The copyright holder for this preprint (which was not certified by peer review) is the author/funder. All rights reserved. No reuse allowed without permission.

125 malleable nature of risk attitudes in rhesus macaques and highlight the importance of

126 using naturalistic tasks for studying cognitive processes.

127

128

129 


\section{RESULTS}

\section{The freely moving patch-leaving task}

133 We examined responses of three macaque subjects in a novel freely moving patch-

134 leaving task (see Methods). We defined the optimal harvest rate as the maximum of the

135 gain function. The gain function is defined by the cumulative reward harvested divided

136 by the total time spent foraging (Charnov, 1976) (figure 1). The optimal harvest is the

137 rate that maximizes the gain function and serves as an index of when a forager should

138 leave a patch. Across patch types the average leave time of subjects produced harvest

139 rates close to the optimal. Had they left patches with no behavioral variability they would

140 have obtained $90 \%$ of the reward an optimal forager would have (subject $\mathrm{C}=93 \%$,

141 subject $\mathrm{K}=89.19 \%$, subject $\mathrm{Y}=87.52 \%$ ). The variability in patch leaving was around 4

142 turns $(\mathrm{C}: \mathrm{sd}=3.4$ turns, $\mathrm{K}: \mathrm{sd}=4.5$ turns, $\mathrm{Y}: \mathrm{sd}=4.8$ turns, $)$. All three exhibited a modest

143 tendency to overharvest, meaning that they overstayed compared to an optimal forager,

144 within a patch by 2-3 turns (average harvest lengths C: 8.636 turns, K: 9.3989 turns, and

145 Y: 10.1599 turns, optimal harvest length 7 turns).

\section{Macaques are indifferent between choice of patch types}

148 Within our foraging task, subjects freely forage within any of the four patches.

149 Thus we can examine how risk influences both the choice of which patch to forage from,

150 in addition to the decision of when to leave a patch. How risk impacts the choice of a

151 patch has been largely unstudied. In our task all four patches have identical mathematical

152 expected value (EV), such that a rate maximizing forager should show no preference 
153 between patch types. However a patch's subjective value may be influenced by the

154 presence of risk, such that a forager would prefer one patch type to the other. Given

155 macaques' robust risk-seekingness, we would expect subjects to forage from risky

156 patches more often than safe patches. Contrary to this prediction, we found no evidence

157 to support a preference for either patch type indicative of subjects basing the choice of

158 patch on average reward rates $(\mathrm{C}: \mathrm{t}(249)=-0.2525, \mathrm{p}=0.8009, \mathrm{~K}: \mathrm{t}(177)=-0.899$,

$159 \mathrm{p}=0.3699, \mathrm{Y}: \mathrm{t}(185)=-1.0267, \mathrm{p}=0.3059)$.

160

\section{Macaques spend more time in safe patches than risky ones}

162 Foragers calibrate patch residence time to the harvest rate within a patch

163 (Charnov, 1976; Stephens \& Krebs, 1986). Their residence time then provides a measure

164 of the subjective value they assign to marginal rewards. This arises out of the putative

165 decision variable that contrasts the marginal gain of staying within the patch against the

166 average rate of reward gained from foraging within the environment. For our task, risk

167 likely influences the subjective evaluation of marginal rewards within risky patches, as

168 on each harvest the subject has no knowledge of whether the reward schedule will step up

169 or down and thus has a noisy estimate of the local patch harvest rate.

170 We next examined residence time in safe and risky patches. All three subjects

171 remained in the safe patches longer than in the risky ones (figure 2) (C: 0.9479 turns,

$172 \mathrm{t}(248)=2.198, \mathrm{p}=0.0144, \mathrm{~d}=0.278 ; \mathrm{K}: 1.35$ turns, $\mathrm{t}(176)=2.0289, \mathrm{p}=0.022, \mathrm{~d}=0.304 ; \mathrm{Y}$ :

1731.17 turns, $t(184)=1.6842, \mathrm{p}=0.0469, \mathrm{~d}=0.247)$. Furthermore, subjects stayed longer in

174 safe patches despite it being suboptimal to do so (specifically, they obtained on average

$17588.71 \%$ of the total harvest rate opposed to $93.15 \%$; C: $91.92 \%$ vs. $95.56 \%, \mathrm{~K}: 88.38 \%$ 
176 vs. $93.56 \%$, Y: $85.82 \%$ vs. $90.32 \%$ ). The tendency of all three subjects to leave risky

177 patches earlier resulted in more optimal harvesting and contrasts with reported biases for

178 overstaying in patch tasks (Nonacs, 2001; Blanchard \& Hayden, 2015). The apparent

179 contrast between optimality and patch staying strongly supports the notion of subjective

180 valuations in favor of avoiding risk as a key component in the decision to leave a patch.

\section{No evidence for win-stay/loose-shift heuristic in guiding patch-leaving}

It is possible that macaques' longer residence times in safe patches is due to a data

184 censoring effect: perhaps they leave when any individual outcome is lower than some

185 threshold. That is, they may obey a win-stay loose-shift heuristic (Hayden et al., 2008;

186 Hayden et al., 2009; Barraclough et al., 2004; Seo \& Lee, 2007). To determine if

187 subjects used this heuristic, we examined the likelihood of leaving a risky patch given the

188 recent history of wins and losses. Even when combining across all sessions, none of the

189 three subjects exhibited a significant preference of increased patch-leaving immediately

190 after losses $(C: t(122)=1.1740, p=0.2427, K: t(82)=0.5465, p=0.5862, Y: t(85)=0.6448$,

$191 \mathrm{p}=.05208)$. Nor did we observe any effect of harvest outcomes two steps back (C:

$192 \mathrm{~F}(3,119)=0.83, \mathrm{p}=0.8009, \mathrm{~K}: \mathrm{F}(3,79)=0.13, \mathrm{p}=0.9413 ; \mathrm{Y}: \mathrm{F}(3,82)=1.44, \mathrm{p}=0.237)$.

193

\section{Risk preferences shift with the coefficient of variation}

195 Given macaques' reported preference for risk we may expect that there is a

196 unique species level difference in how risk is evaluated in the decision making process.

197 Risk preferences may be governed by the experienced variance in reward or by the

198 coefficient of variation (Ludvig et al. , 2014; Weber et al., 2004, Shafir, 2000). In our 
199 task the experienced variance is the deviation in reward delivery times (in this case +/- $1 \mathrm{~s}$

200 solenoid open time). The coefficient of variation is then the deviation in reward delivery

201 divided by the average reward. We investigated whether subjects risk preferences were

202 governed by changes t0 the coefficient of variation by increasing the magnitude of the

203 reward schedule for both feeder types (risky and safe) while keeping variance the same.

204 Increasing the reward magnitude while maintaining variance reduces the coefficient of

205 variation $(\mathrm{CV}($ standard $)=0.5$ vs. $\mathrm{CV}($ rich $)=0.25)$ and has been demonstrated to produce

206 less risk aversion in humans, pigeons, rats, and bees (Ludvig et al., 2014; Weber et al.,

207 2004, Shafir, 2000). By contrast, if subject's risk preferences are influenced by the

208 variance there should be no change in behavior. In all three subjects we saw shifts away

209 from risk-aversion to risk-neutrality/seeking as the coefficient of variation decreased

210 (figure 3.) $(\mathrm{C}: \mathrm{t}(117)=3.3303, \mathrm{p}=0.0005, \mathrm{~d}=0.605, \mathrm{~K}: \mathrm{t}(99)=1.2077, \mathrm{p}=0.115, \mathrm{~d}=0.226$,

$211 Y: \mathrm{t}(94)=1.7483, \mathrm{p}=0.0418, \mathrm{~d}=0.351)$.

Two of the same macaques are risk-prone in computerized task

214 We next analyzed risky choice behavior in two subjects ( $\mathrm{C}$ and $\mathrm{K}$ ) in a standard

215 (not foraging-based, not freely moving) juice gambling task (Strait et al., 2014). Both

216 subjects exhibited strong risk-seeking behavior. On trials with matched expected values

217 subject $\mathrm{C}$ choose the risky option $67 \%(\mathrm{t}(1232)=12.86, \mathrm{p}<0.0001)$ of the time, while

218 subject $\mathrm{K}$ choose the risky option $66 \%$ of the time $(\mathrm{t}(1437)=12.55, \mathrm{p}<0.0001)$.

219 This preference can be quantified using the shape of the utility curve. Both

220 subjects showed convex utility curves (figure 4, C: alpha $=2.284,95 \% \mathrm{CI}=2.584-1.983$;

$221 \mathrm{~K}:$ alpha $=3.632,95 \% \mathrm{CI}=3.822-3.441)$. However within the more naturalistic risky patch 
bioRxiv preprint doi: https://doi.org/10.1101/452151; this version posted October 25, 2018. The copyright holder for this preprint (which was not certified by peer review) is the author/funder. All rights reserved. No reuse allowed without permission.

222 task the same subjects exhibited concave utility curves indicative of strong risk aversion

223 (figure 3, C: alpha $=0.550,95 \% \mathrm{CI}=0.5922-0.508 ; \mathrm{K}:$ alpha $=0.74 \underline{3}, 95 \% \mathrm{CI}=0.889-$

$2240.586)$.

225 


\section{DISCUSSION}

Risk is ubiquitous and unavoidable in the natural environment. Foragers must

228 have strategies for dealing with it. Macaques are found to be risk-seeking in many labs

229 and many contexts (Mccoy \& Platt, 2005) Blanchard, Wilke, and Hayden, 2014;

230 Heilbronner and Hayden, PBR, 2015; (Genest et al., 2016; O’Neill \& Schultz, 2010; Xu

$231 \&$ Kralik, 2014). Risk-seeking in macaques is not due to a preference for variability nor

232 can it be explained by the shape of the utility curve (Heilbronner et al., 2009). It exists

233 alongside a robust ambiguity aversion (Hayden, Heilbronner, \& Platt, 2010), and is

234 partially but not fully explainable as a motivation for information (Blanchard, Hayden, \&

235 Bromberg-Martin, 2015); Kidd and Hayden, 2016).

236 Macaques' risk-seeking is puzzling because most animals are risk-averse. Indeed,

237 a major meta-analysis shows robust risk aversion across dozens of taxa (Kacelnik \&

238 Bateson, 1996). Likewise, humans have been shown to be risk averse (at least for gains)

239 in a large number of cases (Holt and Laury, 2002; Rabin and Thaler, JEP, 2001). Within

240 this, context, the reliable risk-seeking patterns of rhesus macaques presents an important

241 challenge. One approach to reconciling this inconsistency - and more generally, any

242 dissimilarity between species - is to consider their unique evolutionary history, especially

243 their foraging history (Heilbronner et al., 2008; Santos \& Rosati, 2015; Stephens, 2008;

244 Todd \& Gigerenzer, 2007). An alternative approach is to abandon the idea that simple

245 economic tasks measure a robust and invariable trait (Farashahi et al., 2018).

246 This alternative viewpoint starts with the observation that foragers, especially

247 primates, are highly cognitively flexible. They can adapt their strategies rapidly and

248 gracefully to changing circumstances to optimize their intake, perhaps with unobservable 
249 constraints. There is some evidence that macaque risk-seeking is labile: (1) changing the

250 delays between trials can increase or reduce risk-seeking, although it does not produce

251 risk aversion (Hayden \& Platt, 2007); (2) across ostensibly similar tasks, very different

252 patterns of risk attitudes are observed, even as those patterns are consistent between

253 subjects (Farashahi et al., 2018); and (3) when humans are tested for risk attitude in

254 envionments designed to mimic those that produce risk-seeking in macaques, they show

255 trends towards risk-seeking as well (Hayden \& Platt, 2009). Finally, other studies

256 indicate that apparent impulsivity in macaques may be partially attributable to

257 experimental confounds (Hayden, PBR, 2016; Pearson, Hayden, and Platt, Frontiers,

258 2010).

259 These points point towards the possibility that there is something special about the

260 tasks used to measure risk attitudes in macaques that favors risk-seeking behavior

261 (Heilbronner \& Hayden, 2013). To test this idea, we measured risk attitudes in macaques

262 in a more naturalistic context. We embedded the decisions in the context of a patch-

263 leaving task and implemented them in a large space around which macaques could move

264 freely and unconstrained. In this context, we found reliable risk-aversion. Contrary to

265 species level explanations, our results implicate the inherent structure of behavioral tasks

266 as the primary driver of macaque risk preference. This does not mean that species

267 differences have no role in risk attitudes. Instead, they suggest that risk attitudes are so

268 labile that one must carefully consider all parameters of task design when interpreting

269 economic preferences (Stephens and Anderson, 2001). More fundamentally, these results

270 suggest that animals may not have a stable risk attitude, but rather have a consistent but 
bioRxiv preprint doi: https://doi.org/10.1101/452151; this version posted October 25, 2018. The copyright holder for this preprint (which was not certified by peer review) is the author/funder. All rights reserved. No reuse allowed without permission.

14

271 flexible cognitive repertoire that they use when encountering risk. Future studies will be

272 needed to tabulate an inventory of this repertoire.

273 
METHODS

\section{Subjects and Apparatus}

277 Three male rhesus macaques served as subjects for the experiment. Two of the

278 subjects ( $\mathrm{C}$ and $\mathrm{K})$ had previously served as subjects on standard neuroeconomic tasks,

279 including a set shifting task (Sleezer and Hayden, 2016), a diet selection task (Blanchard

280 and Hayden, 2014; Blanchard and Hayden, 2015), and intertemporal choice tasks

281 (Blanchard, Pearson, \& Hayden, 2013). while the third subject (Y) was naïve to all

282 experimental procedures. All three monkeys were fed ad libitum and pair housed within a

283 light and temperature controlled colony room. All research and animal care was

284 conducted in accordance with university IACUC approval and in accord with NIH

285 standards for the care and use of non-human primates.

286 Subjects were behaviorally tested in a large cage (8' L x 9' $\mathrm{W}$ x 8' $\mathrm{H})$ made

287 framed panels consisting of 2 inch wire mesh. This allowed for free movement of the

288 subjects within the cage in three dimensions. Five 55 gallon drum barrels weighted with

289 sand were placed within the cage to serve as perches for the subjects to sit upon. Four

290 juice feeders were placed at each of the four corners of the cage in a rotationally

291 symmetric alignment. The juice feeders consisted of a 16x16 led screen, a lever, buzzer, a

292 solenoid (Parker Instruments), and an arduino uno. Data was collected in MatLab

293 (Mathworks) via Bluetooth communication with each of the juice feeders.

$295 \quad$ Behavioral Tasks

$296 \quad$ Patch leaving risk task 
The patch leaving risk task is designed to mimic the natural depletion of prey

298 items from a patch the longer a subject forages from it (cf. Hayden, Pearson, and Platt,

299 2011; Blanchard and Hayden, 2015). Each feeder was programed to deliver a base reward

300 schedule consisting of an initial $2 \mathrm{sec}$ of juice that decreased by $0.125 \mathrm{sec}$ with each

301 subsequent delivery (turn) (standard environment). In the rich environment, the feeders

302 provided $4 \mathrm{sec}$ of juice that decreased by $0.25 \mathrm{sec}$ each turn. Risk, here defined as

303 variation in reward times, was introduced by programming two of the juice feeders to

304 randomly increase or decrease the juice delivery time by $1 \mathrm{sec}$ in addition to the base

305 reward schedule at a probability of 0.5 . Both feeder types delivered rewards following

306 their respective schedules until reaching the base value of 0 , at which point the patch is

307 depleted and no more rewards were delivered. In practice this depletion process results in

308 identical gain functions over the majority of patch residence times. However because the

309 schedule had a bound at 0 seconds, the tail end of the gain function for risky patches does

310 diverge from safe patches (Figure 1).

311 Two of the four feeders diagonally across from each other were designated as

312 variable feeders, while the other two served as safe feeders (no variation in reward

313 delivery). Feeders were visually identical, although they could be readily discriminated

314 by their position relative to landmarks outside the cage. The feeder designations remained

315 fixed for each subject across experimental days. Each feeder displayed the total amount

316 of prey available within the patch via a blue bar (8x16 LEDs). With each lever press,

317 juice would be delivered and a portion of the blue bar would disappear, explicitly

318 indicating its depletion status. Leaving a feeder to activate any of the other three feeders

319 would cause the previously activated feeder to immediately fully replenish. 


\section{Juice Gambling task}

322 The juice gambling task, which we used as a comparison, was used previously

323 collected for electrophysiology experiments (Strait et al. 2014; Strait et al., 2015a; Strait

324 et al., 2015b). In brief the task consisted of paired choices presented rapidly ( $\sim 3$ sec duty

325 cycle) while subjects sat in a chair. Choices were made rapidly with saccades to spots on

326 a computer screen. Stimuli were colored bars that indicated probability and stakes.

\section{Data Analysis}

\section{Patch leaving risk task}

330 Behavioral data were analyzed in Matlab. For the patch leaving risk task we

331 defined the duration of patch residence as the number of presses at a given juice feeder.

332 Data were combined across experimental days for each subject. In order to analyze the

333 overall optimality of subjects within the foraging task, we used the marginal value

334 theorem (Charnov, 1976) to determine the optimal leaving time.

335

\section{Risk Parameter Estimation}

337 To analyze differences in risk preferences between the juice gambling task and

338 our patch leaving risk task we fit each subject's choice preferences for offer 1 or for the

339 decision to stay in the current patch to the two equations below (Eq. 1 and Eq. 2) using

340 maximum likelihood estimation. In both equations the parameter a functions as an index

341 of risk preference such that a $<1$ implies greater risk avoidance, a $>1$ risk-seeking, and

$342 \quad \mathrm{a}=1$ risk neutrality. 


\section{Eq. 1 Juice Gambling Task}

346

$$
p(\text { choice } \mid \text { offer } 1)=\frac{1}{1+\left(\exp \left(\left(p 1 * v 1^{a}\right)-\left(p 2 * v 2^{a}\right) * b\right)\right.}
$$

$347 \quad \mathrm{p} 1=$ probability of offer 1

$348 \quad \mathrm{v} 1=$ value of offer $1(\mathrm{~s})$

$349 \mathrm{p} 2=$ probability of offer 2

$350 \quad \mathrm{v} 2=$ value of offer $2(\mathrm{~s})$

$351 \quad \mathrm{a}=$ risk preference index

$352 \quad b=$ measure of stochasticity

$$
p(\operatorname{stay} \mid t)=1 /\left(1+\exp \exp \left(\left(\text { threshold }{ }^{a}-V(t)^{a}\right) * b\right)\right.
$$

$358 \quad \mathrm{t}=$ time measured in discrete lever presses

359 threshold $=$ point of indifference between staying and leaving a patch

$360 \mathrm{~V}(\mathrm{t})=$ current reward amount available given the time spent in the patch

$361 \quad a=$ risk preference index

$362 \quad b=$ measure of stochasticity

363

364

365

366 
Figure 1. Gain function (rate as a function of residence time) for safe patches (blue line) and risky patches (red line). The black arrow denotes the abscissa point of the maximum intake rate, and thus the rate-maximizing strategy for both patch types. Due to the programed variation in reward amounts, the gain function for risky patches diverges slightly from the safe patch at long residence times. This divergence arises due to the limitation of reward amounts being bounded at 0 seconds of solenoid open time.

Figure 2. Histogram of residence times for all subjects in safe (blue) and risky (red) patches within the standard environment. Solid lines indicate Gaussian fits to the observed leaving times. Residence times are significantly longer for safe than risky patches, indicating risk aversion.

Figure 3. Histogram of residence time for all subjects in rich environment version of task. Plots follow the same conventions as figure 2. Subjects resided longer in risky patches than safe patches when the entire reward schedule for all feeder types was increased while maintaining the same variance as used in the standard environment.

Figure 4. Plotted utility functions for two subjects who participated in both the feely moving patch task (lower panels) and a standard chaired economic task (upper panels). Dotted lines represent 95\% CI. Two of the same macaques are risk-seeking in the standard task (convex utility curves), and risk-averse the freely moving patch task (concave utility curves). 


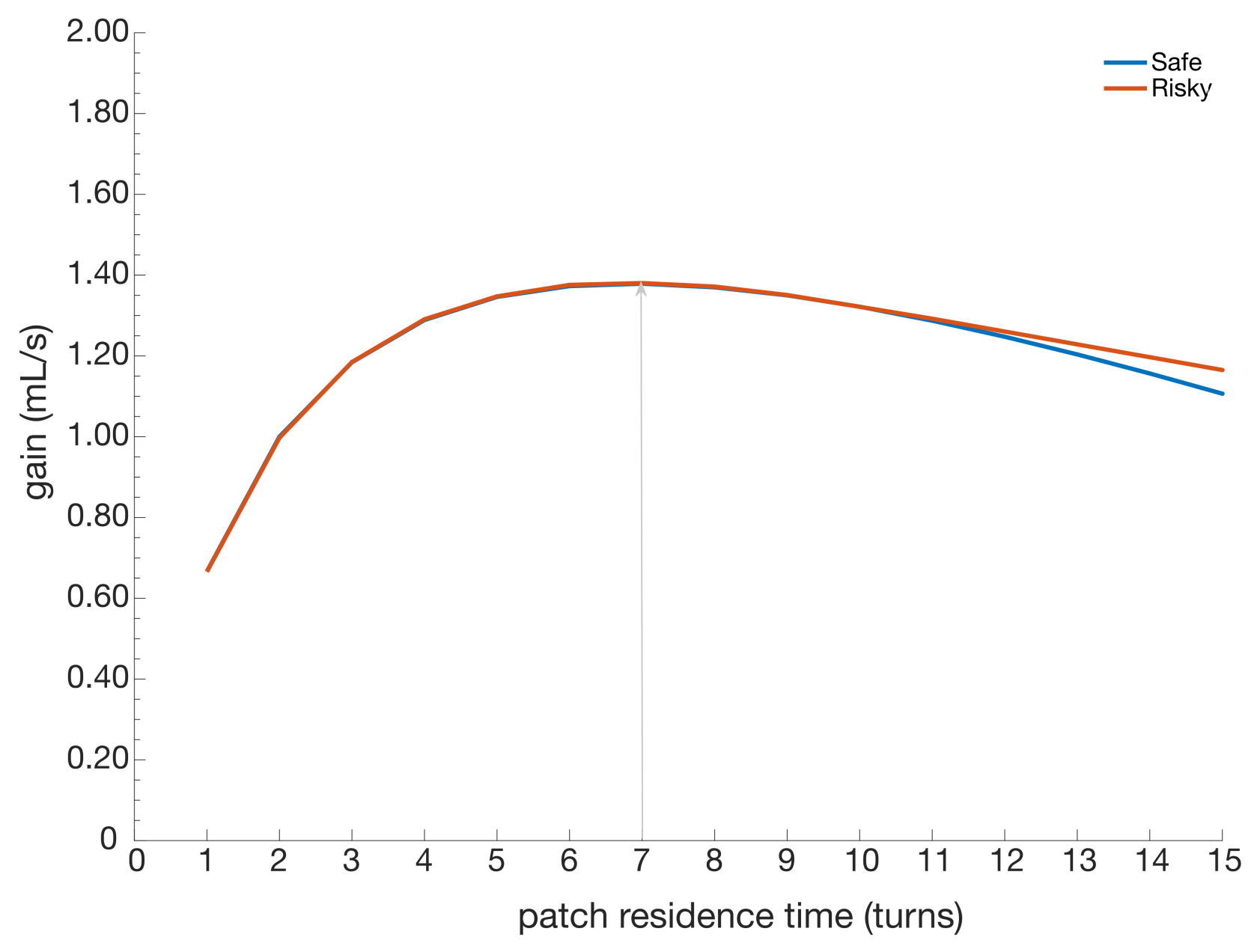


bioRxiv preprint doi: https://doi.org/10.1101/452151; this version posted October 25,2018 . The copyright holder for this preprint (which was not certified by peer review) is the author/funder. All rights reserved. No reuse allowed without permission.
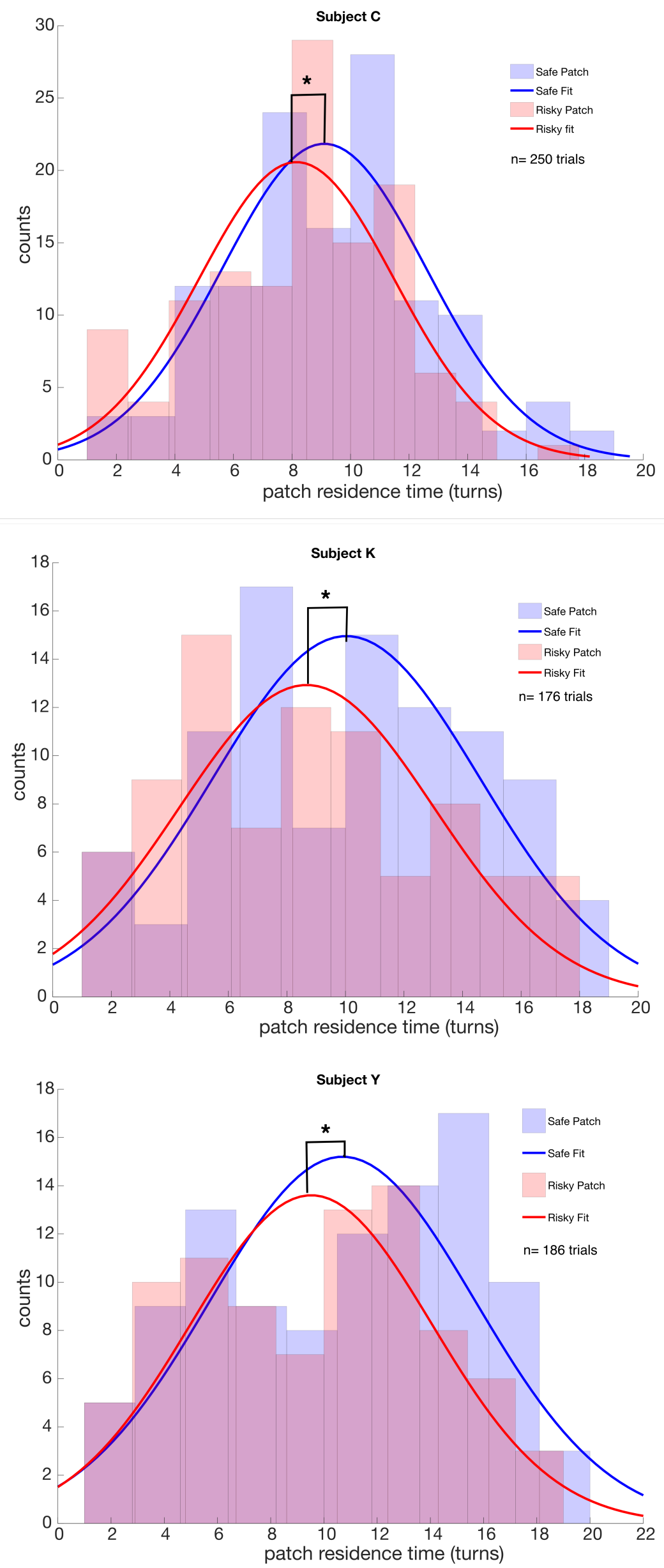
bioRxiv preprint doi: https://doi.org/10.1101/452151; this version posted October 25,2018 . The copyright holder for this preprint (which was not certified by peer review) is the author/funder. All rights reserved. No reuse allowed without permission.
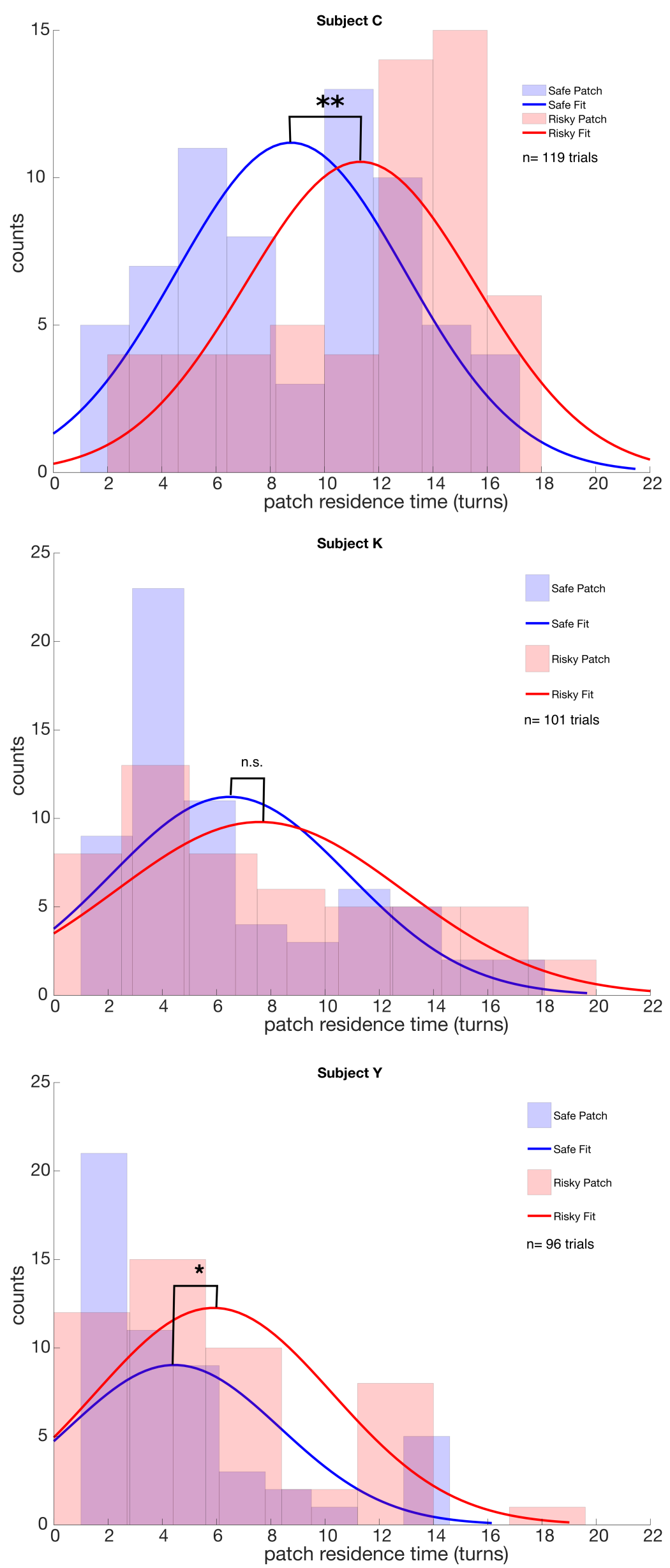
bioRxiv preprint doi: https://doi.org/10.1101/452151; this version posted October 25, 2018. The copyright holder for this preprint (which was not certified by peer review) is the author/funder. All rights reserved. No reuse allowed without permission.
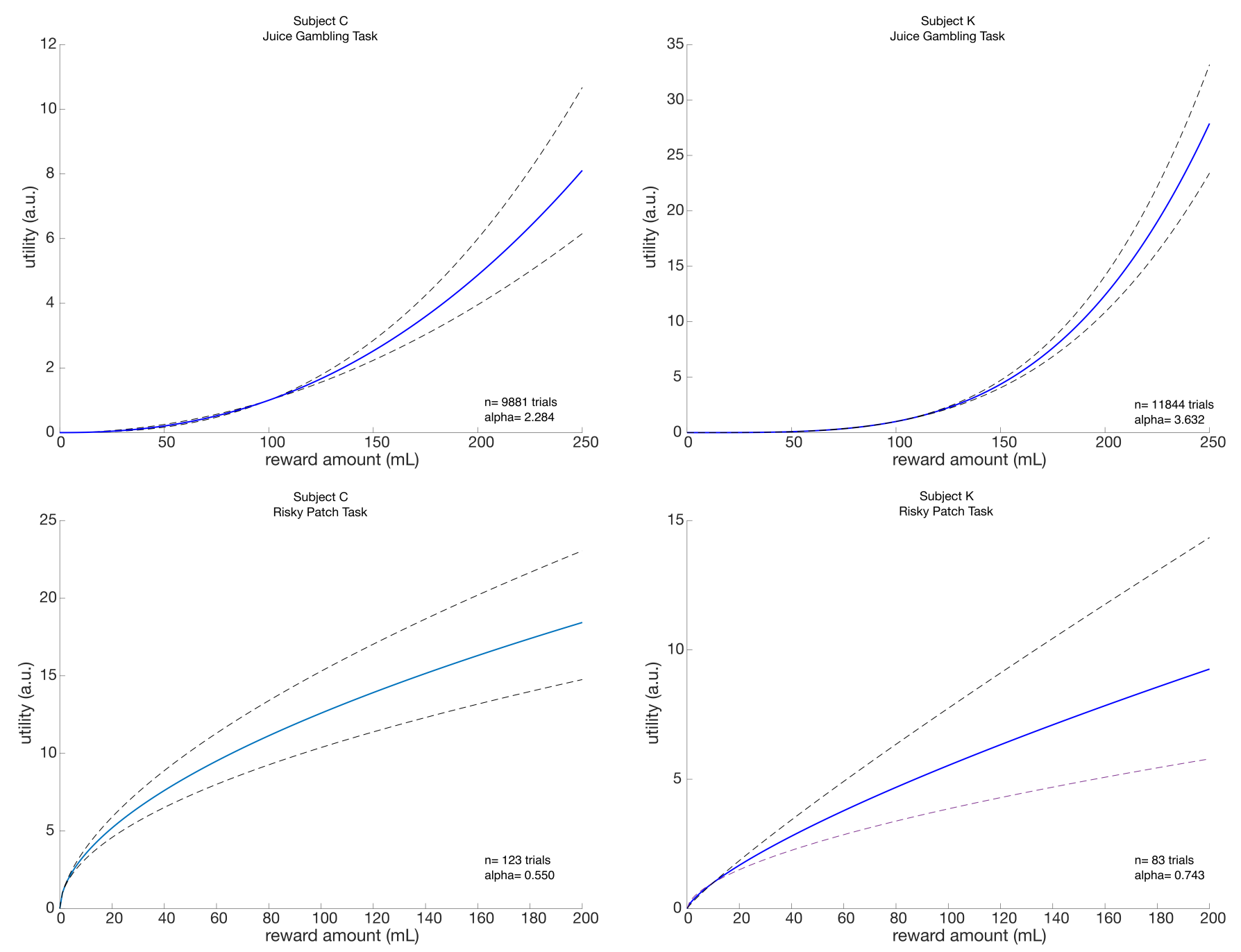
Agetsuma N (1995a) Foraging strategies of Yakushima macaques (Macaca fuscata yakui). Int J Primatol 16:595-609

Barraclough, D. J., Conroy, M.L., \& Lee, D. (2004). Prefrontal cortex and decision making in a mixed-strategy game. Nature Neuroscience, 7, 404-410. doi: 10.1038/nm1209

Blanchard, T. C., \& Hayden, B. Y. (2014). Neurons in dorsal anterior cingulate cortex signal postdecisional variables in a foraging task. Journal of Neuroscience, 34(2), 646-655.

Blanchard, T. C., \& Hayden, B. Y. (2015). Monkeys Are More Patient in a Foraging Task than in a Standard Intertemporal Choice Task. PLoS ONE, 1-11. http://doi.org/10.1371/journal.pone.0117057

Blanchard, T. C., \& Hayden, B. Y. (2015). Ramping ensemble activity in dorsal anterior cingulate neurons during persistent commitment to a decision. Journal of Neurophysiology, 114(4), 2439-2449.

Blanchard, T. C., Hayden, B. Y., \& Bromberg-Martin, E. S. (2015). Orbitofrontal cortex uses distinct codes for different choice attributes in decisions motivated by curiosity. Neuron, 85(3), 602-614. http://doi.org/10.1016/j.neuron.2014.12.050

Blanchard, T. C., Pearson, J. M., \& Hayden, B. Y. (2013). Postreward delays and systematic biases in measures of animal temporal discounting. Proceedings of the National Academy of Sciences, 201310446.

Caraco, T. (1981). Energy budgets, risk and foraging preferences in dark-eyed juncos (Junco hyemalis). Behavioral Ecology and Sociobiology, 8(3), 213-217. http://doi.org/10.1007/BF00299833

Charnov, E. L. (1976). Optimal Foraging, the Marginal Value Theorem. Theoretical Population Biology, 9(2), 129-136.

De Petrillo, F., Ventricelli, M., Ponsi, G., \& Addessi, E. (2015). Do tufted capuchin monkeys play the odds? Flexible risk preferences in Sapajus spp. Animal Cognition, 18(1), 119-130. http://doi.org/10.1007/s10071-014-0783-7

Farashahi, S., Azab, H., Hayden, B., \& Soltani, A. (2018). On the Flexibility of Basic Risk Attitudes in Monkeys. The Journal of Neuroscience, 38(18), 4383-4398. http://doi.org/10.1523/JNEUROSCI.2260-17.2018

Genest, W., Stauffer, W. R., \& Schultz, W. (2016). Utility functions predict variance and skewness risk preferences in monkeys. Proceedings of the National Academy of Sciences, 113(30). http://doi.org/10.1073/pnas.1602217113

Hayden, B. Y. (2018). Economic choice: the foraging perspective. Current Opinion in Behavioral Sciences, 24, 1-6. http://doi.org/10.1016/J.COBEHA.2017.12.002

Hayden, B. Y., Heilbronner, S. R., \& Platt, M. L. (2010). Ambiguity aversion in rhesus macaques. Frontiers in Neuroscience, 4(SEP), 1-7. http://doi.org/10.3389/fnins.2010.00166

Hayden, B. Y., \& Platt, M. L. (2007). Temporal Discounting Predicts Risk Sensitivity in Rhesus Macaques. Current Biology, 17(1), 49-53. http://doi.org/10.1016/j.cub.2006.10.055

Hayden, B. Y., \& Platt, M. L. (2009). Gambling for Gatorade : risk-sensitive decision making for fluid rewards in humans. Animal Cognition, 12, 201-207. 
413

414

415

416

417

418

419

420

421

422

423

424

425

426

427

428

429

430

431

432

433

434

435

436

437

438

439

440

441

442

443

444

445

446

447

448

449

450

451

452

453

454

455

456

457

458 http://doi.org/10.1007/s10071-008-0186-8

Hayden, B. Y., Pearson, J. M., \& Platt, M. L. (2011). Neuronal basis of sequential foraging decisions in a patchy environment. Nature Neuroscience, 14(7), 933

Heilbronner, S. R. (2017). Modeling risky decision-making in nonhuman animals : shared core features. Current Opinion in Behavioral Sciences, 16, 23-29. http://doi.org/10.1016/j.cobeha.2017.03.001

Heilbronner, S. R., \& Hayden, B. Y. (2013). Contextual factors explain risk-seeking preferences in rhesus monkeys. Frontiers in Neuroscience, 7(7 FEB), 1-7. http://doi.org/10.3389/fnins.2013.00007

Heilbronner, S. R., Rosati, A. G., Stevens, J. R., Hare, B., \& Hauser, M. D. (2008). A fruit in the hand or two in the bush ? Divergent risk preferences in chimpanzees and bonobos. Biology Letters, 4(March), 246-249. http://doi.org/10.1098/rsbl.2008.0081

Kacelnik, A., \& Abreu, F. B. e. (1998). Risky Choice and Weber' s Law. Journal Theoretical Biology, 194(jt980763), 289-298.

Kacelnik, A., \& Bateson, M. (1996). Risky Theories - The Effects of Variance on Foraging Decisions 1. American Zoologist, 434, 402-434.

Kagel, J. H., MacDonald, D. N., Battalio, R. C., White, S., \& Green, L. (1986). Risk aversion in rats (Rattus norvegicus) under varying levels of resource availability. Journal of Comparative Psychology, 100(2), 95-100. http://doi.org/10.1037/07357036.100.2.95

Kanheman, D., \& Tversky, A. . (1979). Prospect theory: An analysis of decision under risk. Econometrica, 47, 263-291.

Knutson, B., \& Bossaerts, P. (2007). Neural Antecedents of Financial Decisions. Journal of Neuroscience, 27(31), 8174-8177. http://doi.org/10.1523/JNEUROSCI.156407.2007

Ludvig, E. A., Madan, C. R., Pisklak, J. M., \& Spetch, M. L. (2014). Reward context determines risky choice in pigeons and humans. Biology Letters, 10(8). http://doi.org/10.1098/rsbl.2014.0451

Marsh, B., \& Kacelnik, A. (2002). Framing effects and risky decisions in starlings. Proceedings of the National Academy of Sciences, 99(5), 3352-3355.

Mccoy, A. N., \& Platt, M. L. (2005). Risk-sensitive neurons in macaque posterior cingulate cortex. Nature Neuroscience, 8(9), 1220-1227. http://doi.org/10.1038/nn1523

Nonacs, P. (2001). State dependent behavior and the marginal value theorem. Behavioral Ecology, 12(1), 71-83.

O’Donoghue, T., \& Somerville, J. (2018). Modeling Risk Aversion in Economics. Journal of Economic Perspectives, 32(2), 91-114. http://doi.org/10.1257/jep.32.2.91

O’Neill, M., \& Schultz, W. (2010). Coding of reward risk by orbitofrontal neurons is mostly distinct from coding of reward value. Neuron, 68(4), 789-800. http://doi.org/10.1016/j.neuron.2010.09.031

Peters, S. K., Dunlop, K., \& Downar, J. (2016). Cortico-Striatal-Thalamic Loop Circuits of the Salience Network: A Central Pathway in Psychiatric Disease and Treatment. Frontiers in Systems Neuroscience, 10(December), 1-23. http://doi.org/10.3389/fnsys.2016.00104

Preuschoff, K., Quartz, S. R., \& Bossaerts, P. (2008). Human Insula Activation Reflects Risk Prediction Errors As Well As Risk. Journal of Neuroscience, 28(11), 2745- 
2752. http://doi.org/10.1523/JNEUROSCI.4286-07.2008

Proctor, D., Williamson, R. A., Latzman, R. D., de Waal, F. B. M., \& Brosnan, S. F. (2014). Gambling primates: Reactions to a modified Iowa Gambling Task in humans, chimpanzees and capuchin monkeys. Animal Cognition, 17(4), 983-995. http://doi.org/10.1007/s10071-014-0730-7

Real, L. A. (1990). Search Theory and Mate Choice . I . Models of Single-Sex Discrimination Author ( $\mathrm{s}$ ): Leslie Real Source: The American Naturalist, Vol . 136, No . 3 ( Sep ., 1990 ), pp . 376-405 Published by: The University of Chicago Press for The American Society o. The American Naturalist, 136(3), 376-405.

Santos, L. R., \& Rosati, A. G. (2015). The Evolutionary Roots of Human Decision Making. Annual Reviews Psychology, 66, 321-347. http://doi.org/10.1146/annurevpsych-010814-015310. The

Sayers, K., \& Menzel, C. R. (2017). Risk sensitivity, phylogenetic reconstruction, and four chimpanzees. Behavioral Ecology and Sociobiology, 71(1). http://doi.org/10.1007/s00265-016-2234-8

Seo, H., \& Lee, D. (2007). Temporal filtering of reward signals in the dorsal anterior cingulate cortex during a mixed strategy game. Journal of Neuroscience, 27(31), 8366-8377

Shafir, S. (2000). Risk-sensitive foraging: The effect of relative variability. Oikos, 88 , 663-669.

Sleezer, B.J., \& Hayden, B.Y. (2016). Differential contributions of ventral and dorsal striatum to early and late phases of cognitive set reconfiguration. Journal of Cognitive Neuroscience, 28(12), 1849-1864

So, N.-Y., \& Stuphorn, V. (2010). Supplementary Eye Field Encodes Option and Action Value for Saccades With Variable Reward. Journal of Neurophysiology, 104(5), 2634-2653. http://doi.org/10.1152/jn.00430.2010

Stauffer, X. W. R., Lak, X. A., Bossaerts, P., \& Schultz, W. (2015). Economic Choices Reveal Probability Distortion in Macaque Monkeys. The Journal of Neuroscience, 35(7), 3146-3154. http://doi.org/10.1523/JNEUROSCI.3653-14.2015

Stephens, D. W. (2008). Decision ecology : Foraging and the ecology of animal decision making. Cognitive Affective Behavioral Neuroscience, 8(4), 475-484. http://doi.org/10.3758/CABN.8.4.475

Stephens, D. W., \& Krebs, J. R. (1986). Foraging Theory. Princenton: Princenton University Press.

Stevens, J. R., Rosati, A. G., Ross, K. R., \& Hauser, M. D. (2005). Will travel for food: Spatial discounting in two New World monkeys. Current Biology, 15(20), 18551860. http://doi.org/10.1016/j.cub.2005.09.016

Strait, C. E., Blanchard, T. C., \& Hayden, B. Y. (2014). Reward value comparison via mutual inhibition in ventromedial prefrontal cortex. Neuron, 82(6), 1357-1366. http://doi.org/10.1016/j.neuron.2014.04.032

Strait, C. E., Sleezer, B. J., \& Hayden, B. Y. (2015a). Signatures of value comparison in ventral striatum neurons. PLoS Biology, 13(6), e1002173

Strait, C. E., Sleezer, B. J., Blanchard, T. C., Azab, H., Castagno, M. D., \& Hayden, B. Y. (2015b). Neuronal selectivity for spatial positions of offers and choices in five reward regions. Journal of Neurophysiology, 115(3), 1098-1111.

Todd, P. M., \& Gigerenzer, G. (2007). Environments That Make Us Smart. Current 

Directions in Psychological Science, 16(3), 167-171. http://doi.org/10.1111/j.14678721.2007.00497.x common for low-stakes gambles? Organizational Behavior and Human Decision Processes, 97, 31-46. http://doi.org/10.1016/j.obhdp.2005.03.001 and Lower Animals: Risk as Variance or Coefficient of Variation. Psychological Review, 111(2), 430-445. http://doi.org/10.1037/0033-295X.111.2.430

Wilson, M. J., \& Vassileva, J. (2018). Decision-making under risk, but not under ambiguity, predicts pathological gambling in discrete types of abstinent substance users. Frontiers in Psychiatry, 9(JUN), 1-10. http://doi.org/10.3389/fpsyt.2018.00239

Xu, E. R., \& Kralik, J. D. (2014). Risky business : rhesus monkeys exhibit persistent preferences for risky options. Frontiers in Psychology, 5(April), 1-12. http://doi.org/10.3389/fpsyg.2014.00258

Yamada, H., Tymula, A., Louie, K., \& Glimcher, P. W. (2013). Thirst-dependent risk preferences in monkeys identify a primitive form of wealth. Proceedings of the National Academy of Sciences, 110(39), 15788-15793. http://doi.org/10.1073/pnas.1308718110//DCSupplemental.www.pnas.org/cgi/doi/10.1073/pnas.1308718110 